\title{
2. DISPENSA DE EMPREGADO PORTADOR DO VÍRUS HIV
}

Recurso de Revista , princípios constitucionais de dignidade da pessoa humana e dos valores sociais do trabalho

Acórdão Inteiro Teor

ORIGEM

Tipo: RR Número: 439041 Ano: 1998

ACÓRDÃO (3 $3^{\text {a }}$ Turma) CFB/jv/su

RECURSO DE REVISTA. PORTADOR DO VÍRUS HIV. CONHECIMENTO DO EMPREGADOR. LEI 7.670, DE 08/09/88. ART. 476/CLT. DESPEDIDA 
OBSTATIVA. Ao dispensar o empregado, sem justa causa, portador da síndrome à época (com doença já manifestada) a Recorrida impediu a obtenção do benefício previdenciário, quando usufruiria de licença não remunerada. Princípios constitucionais de dignidade da pessoa humana e dos valores sociais do trabalho. Art. 1\%/III/IV/CF. Recurso do Reclamante provido.

Vistos, relatados e discutidos estes autos de Recurso de Revista TSTRR- 439.041/98.5, em que é Recorrente GILMAR RAMOS DA SILVA e Recorrida SÃO PAULO TRANSPORTE S/A.

A 9 ${ }^{\mathrm{a}}$ Turma do Tribunal Regional do Trabalho da $2^{\mathrm{a}}$ Região, mediante 0 acórdão de fls. 109/111, proveu o recurso ordinário da Reclamada para afastar a condenação à reintegração e consectários, pois, em síntese, na época da dispensa do Reclamante (agosto de 1993), portador do vírus HIV, inexistia no direito positivo do trabalho norma asseguradora da reintegração.

O Reclamante interpõe recurso de revista (fls. 112/120) sustentando que a decisão recorrida fere os arts. $3^{\circ}$, inciso IV e $7^{\circ}$, inciso I, da Constituição Federal, o 141, inciso III, do Decreto-Lei n. 611/92, 476, 845, 846 e 847 da CLT, bem como dispositivos da Lei n. 7.670/88, além de divergir do entendimento da jurisprudência colacionada.

$\mathrm{O}$ apelo foi admitido (fl. 122).

Contra-razões foram apresentadas (fls. 347/359).

Não há manifestação do Ministério Público do Trabalho.

É o relatório.

VOTO

\section{1 - CONHECIMENTO}

Atendidos os pressupostos ordinários de admissibilidade do Recurso de Revista, examino os específicos.

\section{1 - REINTEGRAÇÃO. PORTADOR DO VÍRUS HIV}

No particular, o acórdão revisando (fls. 110/111) asseverou que na época da dispensa, a Recorrida sabia das condições em que se encontrava o Recorrente, portador do vírus HIV, acrescentando que, todavia, tal circunstância seria insuficiente para respaldar a condenação, notadamente se o obreiro foi dispensado por motivos técnicos.

O acórdão ainda asseverou que a Constituição Federal preceitua que a garantia de emprego será prevista em lei complementar (art. $7^{\circ}$, inc. I), sendo que o ADCT apenas excepcionou a gestante e os cipeiros e, posteriormente, a Lei n. 8.213/91 (art. 118) incluiu a garantia de emprego ao acidentado por 12 meses.

Assim, após entender que a situação de saúde do Reclamante não Ihe poderia enquadrar nas normas que definem o acidente do trabalho, qual 
seja, doença profissional ou doença do trabalho, concluiu referido julgado que, "ainda que se leve em conta o aspecto humano e social, as empresas de modo algum estão obrigadas legalmente a garantirem emprego e salários aos doentes que não se enquadram na legislação própria, exceto se tiverem implementado programa de prevenção ou ajuda ao portador soropositivo, como para aquisição de medicamento específico ou celebrado convenção coletiva" (fl. 111), o que não era o caso dos autos, pois, à época da dispensa - agosto de 1993 -, inexistia no direito positivo do trabalho norma asseguradora da reintegração, em geral ou especificamente, esta garantia. $O$ aresto de fls. $118 / 119$ possibilita o conhecimento do tema por conflito de teses, à medida que expressa posição no sentido de que, quando a doença já se manifesta, a dispensa sem justo motivo, mesmo não comprovada a discriminação pela doença letal, é vedada, pois caracteriza-se como obstativa ao percebimento de direito previdenciário, entendimento, em última circunstância, conflitante com o do acórdão recorrido, que considera a falta de norma legal ou negociada prevendo o contrário, o poder potestativo de o empregador dispensar livremente o empregado aidético.

Conheço, por divergência jurisprudencial.

2- MÉRITO

\section{1 - REINTEGRAÇÃO. PORTADOR DO VÍRUS HIV}

Não obstante a falta de normas legais ou convencionais na época da dispensa do Recorrente que garantiriam a reintegração de trabalhador afetado pelo vírus HIV, a situação é singular, e é por este prisma que a controvérsia deve ser enfrentada.

Assim, considerando o estigma que o portador do vírus HIV "carrega", desenvolvida ou não a doença - AIDS —, e tendo em vista que a dignidade da pessoa humana é um dos pilares em que se sustenta o Estado Democrático de Direito (Constituição Federal, art. $1^{\circ}$, inciso III), o Direito do TrabaIho Brasileiro, até pelo princípio da hierarquia de normas, deve ser fiel a esse princípio.

Destarte, até também por solidariedade, a empresa deve, de todas as formas, procurar manter o vínculo empregatício do empregado soropositivo ou aidético, e até mesmo ajudá-lo para que receba os benefícios da Previdência Social, ainda que o motivo da dispensa do empregado não tenha sido a contaminação ou a doença, caso dos autos.

Insta lembrar que o Tribunal Superior do Trabalho, julgando Recurso Ordinário em Mandado de Segurança, decidiu que o empregado portador do vírus HIV tem direito à reintegração, mormente quando a dispensa se deu de forma a impedir a estabilidade que viria, conforme se vê do seguinte precedente: 
"MANDADO DE SEGURANÇA . SENDO O TRABALHADOR PORTADOR DE DOENÇA QUE PODE LEVÁ-LO À MORTE, ESTANDO PRESTES A ADQUIRIR O DIREITO À ESTABILIDADE NO EMPREGO, HAVENDO SIDO DEMITIDO DE FORMA OBSTATIVA E SENDO ABSOLUTAMENTE NECESSÁRIO O EXERCICCIO DE SUA ATIVIDADE PROFISSIONAL NO COMBATE AO MAL QUE O AFLIGE, O TRANSCURSO DO TEMPO É IMPRESCINDÍVEL PARA QUE SE EVITE RESTAR PREJUDICADO O SEU DIREITO. O 'PERICULUM IN MORA' É O PRÓPRIO RISCO DO PERECIMENTO DA VIDA DO TRABALHADOR. DE QUE ADIANTARIA AO EMPREGADO SAGRAR-SE VENCEDOR NUMA AÇÃO TRABALHISTA APÓS A SUA MORTE? O DIREITO DEVE SER ÁGIL E SER APLICADO NO MOMENTO CERTO, SOB PENA DE TORNAR-SE INÓCUO, MORMENTE NESTE CASO CONCRETO, ONDE MAIS IMPORTANTE QUE OS EVENTUAIS VALORES MONETÁRIOS EM DISCUSSÃO É A PRÓPRIA VITAL NECESSIDADE DE O EMPREGADO EXERCER SUAS FUNÇÕES ENQUANTO APTO PARA TAL. RECURSO CONHECIDO E DESPROVIDO." (Fonte: Proc. TST-ROMS-110056/94, SDI, Relator Ministro Armando de Brito, DJ de 31/03/1995).

Em face do exposto, dou provimento para determinar a reintegração do obreiro, com pagamento dos salários vencidos e vincendos e todas as vantagens que auferiria se estivesse trabalhando, ou, na impossibilidade concreta da reintegração, o pagamento destas vantagens até a data efetiva em que o Recorrente começar a receber os benefícios da Previdência Social.

\section{ISTO POSTO}

ACORDAM os Ministros da Terceira Turma do Tribunal Superior do Trabalho, unanimemente, conhecer do recurso, por divergência jurisprudencial e, no mérito, dar-Ihe provimento para determinar a reintegração do obreiro, com pagamento dos salários vencidos e vincendos e todas as vantagens que auferiria se estivesse trabalhando, ou, na impossibilidade concreta da reintegração, o pagamento destas vantagens até a data efetiva em que o Recorrente começar a receber os benefícios da Previdência Social.

Brasília, 13 de junho de 2001.

MINISTRO JOSÉ LUIZ VASCONCELLOS

Presidente

JUIZ CONVOCADO CARLOS FRANCISCO BERARDO

Relator 


\section{COMENTÁRIOS}

\section{Candy Florêncio Thomé(") \\ Lilian Pereira da Silva" \\ Marcelo Ribeiro dos Santos Bicudo"}

A $3^{\text {a }}$ Turma do Tribunal Superior do Trabalho, sob a titularidade do Ministro Dr. José Luiz Vasconcellos e do Juiz Relator Dr. Carlos Francisco Berardo, muito bem decidiu, em face de situação singular do caso em tela, tendo em vista a dignidade da pessoa humana e observando os princípios do direito do trabalho, da função social da propriedade e do direito sanitário. Brilhante decisão, pois o acolhimento do entendimento da recorrida implicaria a impossibilidade de obtenção de qualquer benefício previsto na Constituição ou na legislação infraconstitucional, legais instituidoras de direitos e garantias, bem como tornaria inúteis todas as normas constitucionais pertinentes.

No que concerne aos princípios do direito do trabalho, garantiu-se ao obreiro sua reintegração ao trabalho com todas as verbas e vantagens que auferiria como se estivesse trabalhando, bem como, garantiu-se também, o recebimento de tais verbas até o início do recebimento do benefício da Previdência Social, caso fosse confirmada a impossibilidade concreta de sua reintegração, atendo-se ao princípio da continuidade das relações de emprego.

A empresa contratante, como afirmado no voto quanto ao mérito da decisão, tem o dever, até por solidariedade, sob todas as formas, de procurar manter o vínculo empregatício do empregado soropositivo ou aidéti$c o$, e até mesmo ajudá-lo para que receba o benefício da Previdência Social.

Outro entendimento não pode prosperar, para que se cumpra os princípios firmados em nossa Carta Constitucional, que, já em seu Preâmbulo, compromete o povo brasileiro, a buscar uma Sociedade Fraterna, Pluralista e Sem Preconceitos. Os princípios da Solidariedade estão presentes. No trato das garantias dos direitos individuais, nossa Carta Constitucional aponta o dever de se atender às finalidades de uma Sociedade Fraterna, e de que toda norma infraconstitucional the deve fidelidade.

Com tal princípio vemos o disposto no Título II de nossa Constituição Federal - "Dos Direitos e Garantias Fundamentais", Capítulo I "Dos Direitos e Deveres Individuais e Coletivos", em seu art. 5, inciso XXII, que aqui reproduzimos:

(*) Participantes do programa de Aprimoramento Profissional da FUNDAP - 2001/2002, em Direito Sanitário - Faculdade de Saúde Pública - USP. 
Art. $5^{\circ}$ Todos são iguais perante a lei, sem distinção de qualquer natureza, garantindo-se aos brasileiros e aos estrangeiros residentes no País a inviolabilidade do direito à vida, à liberdade, à segurança e à propriedade, nos termos seguintes:

XXII - é garantido o direito de propriedade;

Assim, pelo nosso regramento maior, fica claro e explícito que a todos os brasileiros e aos estrangeiros residentes no País a inviolabilidade do direito de propriedade, propriedade aqui no seu sentido amplo, tudo aquilo que é obtido de forma lícita. No inciso XXIII, determina-se que "a propriedade atenderá a sua função social", dando o inequívoco preceito ao fim à que se destina a propriedade de brasileiros e estrangeiros residentes no País, de tudo aquilo que obtido de forma lícita, se destine a ter sua função social. Tal disposição, que deve nortear toda norma infraconstitucional, é encontrada, mais uma vez, no Título VII da Constituição Federal - "Da Ordem Econômica e Financeira", Capítulo I - "Dos Princípios Gerais da Atividade Econômica" em seu art. 170, inciso III:

Art. 170. A ordem econômica, fundada na valorização do trabalho humano e na livre iniciativa, tem por fim assegurar a todos existência digna, conforme os ditames da justiça social, observados os seguintes princípios:

III - função social da propriedade;

Aqui, mais uma vez, não se confunde nossa proposta, redigida pelo Constituinte, de que a ordem econômica, toda atividade geradora de recurso, será fundada na valorização do trabalho humano, para o fim de se assegurar a todos, trabalhadores e empresários, existência digna. Humanos, brasileiros e estrangeiros residentes no País com o dever de agir conforme os ditames da justiça social, para uma vida em Sociedade Fraterna, Pluralista e Sem Preconceitos e comprometidos para que seja observado o princípio da função social da propriedade.

O Voto relatado na decisão não nos deixa dúvida da acertada decisão, porquanto aponta a dignidade da pessoa humana como um dos pilares em que se sustenta o Estado Democrático de Direito (Constituição Federal, art. 1, inciso III), e mais, até também por solidariedade, a empresa deve, de todas as formas, ajudá-lo para que receba o benefício da Previdência Social. A empresa que tem o poder dos direitos de propriedade, de seu capital, logo, tem, também, o dever de ajudar o empregado, sob todas as formas, por solidariedade, para que se cumpra a função da sua propriedade, ser ela a promotora que irá assegurar ao seu trabalhador uma existência digna, como ditame para uma justiça social, ser esta sua função para uma Sociedade Fraterna. 
Como Princípio da Função Social da Propriedade vejamos o que nos ensina Grace Virgínia Ribeiro de Magalhães Tanajura, em seu livro "Função Social da Propriedade Rural" (São Paulo: LTr, 2000 pp. 20/21). Os positivistas do século passado e início deste se tornaram precursores da Função Social da Propriedade. Augusto Comte apresentou a semente que León Duguit melhor elaborou em sua obra "Transformações Gerais do Direito Privado desde o Código de Napoleão", em 1912, em Paris. A idéia de Duguit é de uma Propriedade-Função, criticada por alguns autores que alegam que a propriedade "já contém" a função que a ela está jungida. Ou seja, o direito de propriedade é garantido pela ordem jurídica, todavia deve ser exercido à luz da Função Social que the é inerente. Para usar uma expressão metafórica, diz-se que o direito de propriedade é o corpo, e a função social é a alma, elementos inseparáveis, mas distintos, que se mantêm vivos enquanto ligados.

O ensinamento apresentado por Grace Virgínia Ribeiro de Magalhães Tanajura, com sua história e metáfora só nos deixa mais confortáveis, porquanto nossa sociedade fez adotar o direito em Carta Constitucional para o exercício das garantias individuais, da propriedade, e de que esse direito de propriedade sempre seja exercido atendendo a sua função social.

Fábio Konder Comparato, em seu trabalho apresentado no painel sobre "a função social da propriedade", no XII Congresso Nacional de Procuradores de Estado, realizado em Salvador-BA, de $1^{\circ}$ a 5.9.86, e publicado na Revista de Direito Mercantil n. 63, julho/setembro 1986, sob o título "Função Social da Propriedade dos Bens de Produção", trata de forma distinta os Deveres Sociais do Controlador de Empresas. Não é ele, o controlador, o titular da Propriedade, Capital Financeiro que viabiliza a constituição da Empresa, (p. 77).

Quando os bens de produção acham-se incorporados a uma exploração empresarial, como vimos, a discutida função social já não é um poderdever do proprietário, mas do controlador. Malgrado o caráter elementar da distinção, importa reafirmar aqui que poder de controle não se confunde com propriedade. Não é um direito real, portanto, de caráter absoluto, incidindo sobre uma coisa, mas um poder de organização e de direção, envolvendo pessoas e coisas. A causa dessa persistente confusão conceitual está, sem dúvida, no fato de que, em regime capitalista, o poder de controle empresarial funda-se na propriedade do capital ou dos títulos - valores representativos do capital da empresa. Finalmente, os deveres sociais do controlador de empresas, estabelecidos, em tese, em algumas normas do direito positivo, somente poderão ser desempenhados, com clareza e cobrados com efetividade, quando os objetivos sociais a serem atingidos forem impostos no quadro de uma planificação vinculante para o Estado e diretiva da atividade econômica privada. 
Em seu Resumo, Comparato conclui: A chamada função social da propriedade representa um poder-dever positivo, exercido no interesse da coletividade, e inconfundivel, como tal, com as restrições tradicionais ao uso de bens próprios. A afirmação do princípio da função social da propriedade, sem maiores especificações e desdobramentos, tem-se revelado, pela experiência constitucional germânica, tecnicamente falha.

Aqui foi possível aprender com a constituição germânica, citada no trabalho publicado em 1986, como tecnicamente falha, para que nossos constituintes fossem precisos. No art. 170, inciso II e III, Capítulo I - Dos Princípios Gerais da Atividade Econômica", de nossa Constituição, Federal de 1988 dispõem: "A ordem econômica, fundada na valorização do trabalho humano e na livre iniciativa, tem por fim assegurar a todos existência digna, conforme os ditames da justiça social, observados os seguintes princípios:

\section{II - propriedade privada;}

III - função social da propriedade;"

Ditando, assim, aos detentores do direito da propriedade privada (inciso II), de bens de capital, a observação, também, dos direitos garantidos ao trabalho humano com o fim de assegurar existência digna, conforme os ditames da justiça social. Em suma, garantir-se o exercício, a ação dos bens de capital, destinados à função social de tal propriedade. A pessoa física, proprietária dos bens de capital, que constituiu a empresa para o desenvolvimento da atividade econômica, se integra a nova personalidade, agora juridical, que nomeia controladores, tal qual procuradores com poderes específicos, não isentos da prestação de contas por atos de ação e omissão aos objetivos sociais da entidade (empresa) constituída, respondendo sim, como proprietário dos bens de capital que, tem o poder-dever de observar o princípio "função social da propriedade".

Como citado no acórdão, “...a empresa deve, de todas as formas, procurar manter o vínculo empregatício do empregado soropositivo ou aidético,...". A empresa, na pessoa de direito, o proprietário dos bens de capital que originou, possibilitou, sua constituição, ou seu nomeado controlador, cumpridor dos objetivos sociais à que foi constituida, tem o poderdever de observar, e agora cumprir com a ordem judicial das ações que irão oferecer ao brasileiro (ou estrangeiro residente no País) uma Sociedade Fraterna, a função social de uma propriedade, além de seguir o princípio trabalhista da continuidade das relações de emprego, bem como respeitar os aspectos da Saúde do trabalhador.

Concluindo, nosso judiciário deu mostra do engajamento dos poderes do Estado Democrático que vivemos, sob a égide de uma Constituição Social que objetiva a dignidade do ser humano, mais ainda, em precário estado de saúde. 


\section{REFERÊNCIAS}

Constituição da República Federativa do Brasil, promulgada em 5 de outubro de 1988, São Paulo: Editora Saraiva, 30ª ed., 2002.

TANAJURA, Grace Virgínia Ribeiro de Magalhães. Função social da propriedade rural, São Paulo: LTr, 2000.

COMPARATO, Fábio Konder. Função Social da Propriedade dos Bens de Produção, Revista de Direito Mercantil, n. 63 julho/setembro, 1986. 